\title{
Д.А. Квашнина
}

\section{ФИЛОСОФСКИЕ АСПЕКТЫ ВЛИЯНИЯ ИСКУССТВЕННОГО ИНТЕЛЛЕКТА НА СОЦИУМ}

\begin{abstract}
Тема искусственного интеллекта - одна из самых важных в контексте будущего человечества. Его потенциал представляет большую угрозу существованию человека как вида. Актуальность данной статьи заключается в том, что безопасность бытия человечества рассматривается с точки зрения системы искусственного интеллекта, неотьемлемой частью которой являются сферы наноиндустрии, робототехники и стратегии информатизации общества.

Ключевые слова: искусственный интеллект, безопасность, робототехника, наноиндустрия, киберпространтво.
\end{abstract}

Сегодня неоспоримым фактом является то, что внедрение систем искусственного интеллекта в жизнедеятельность человека имеет кардинальное значение. По мнению В.А. Лекторского, широкомасштабное развитие сфер наноиндустрии подменяет сущность человека как некоего биосоциального существа, «одновременно живущего в разных мирах: не только в мире физических и биологических процессов, но и в мире культуры, не только в мире естественном, но и в мире искусственном» [1. С. 6]. Возможности систем искусственного интеллекта действительно поражают. Такие системы способны полностью заменить человека, например, при управлении воздушным, наземным, водным транспортом, предоставлении некоторых медицинских услуг (экспертные системы), предоставлении образовательных услуг, производстве и т.д. Но подобное взаимодействие человека с искусственным интеллектом таит в себе угрозы безопасности как личности, так и общества, государства в целом. Обеспечение безопасности человечества четко проявляется в процессах локализации социогенных источников опасности, а именно, «деятельности социальных институтов, структур, субъектов с сознательной или бессознательной деструктивной направленностью» [2. С. 28].

В изучении проблем взаимосвязи искусственного интеллекта и безопасности социума особое внимание уделяется вопросам, связанным со сложностями при создании современной технологической базы (средств, методов) для проектирования компьютерных систем, способных решать интеллектуальные задачи, например, в области робототехники; с весьма неоднозначными процессами, направленными на создание и формирование более эффективной безопасной образовательной среды в целях модификации возможностей головного мозга человека, «перезагрузкой сознания», новыми механизмами мышления, генетическими, психическими и особенностями личности, погружаемой в суперкомпьютер.

Стремление современных ученых изменить траекторию развития и осуществить тотальную переориентацию «человека природного» на «человека техногенного» с применением методов эвристического кибернетического 
моделирования, вероятно, может привести к качественному изменению природной сущности человека, появлению киборгов и трансформации общественных отношений. Здесь система искусственного интеллекта понимается как результат некой деятельности человека, способного логически размышлять, контролировать и управлять своими действиями, выражать свои чувства и эмоции, способного обосновать и скорректировать свои решения в зависимости от изменяющихся условий окружающей среды. Искусственный интеллект - это высокий результат достижений техногенной цивилизации, сложная система взаимосвязей (глобальные поисковики) и основа для создания всеобъемлющих информационных системных образований. В ближайшей перспективе активное применение компьютерных технологий, нанобиотехнологий может позволить переформатировать поведение человека, изменить общественные отношения и повлиять на экзистенциональные характеристики личности. «Сегодня экономическое и социальное развитие во всё большей степени начинает определяться так называемыми NBICтехнологиями: нано-, био-, информационными и когнитивными. Сами эти технологии стали возможны на основе научного изучения соответствующих процессов» [1. С. 5]. Следовательно, системы искусственного интеллекта, учитывая достижения в сфере современной робототехники, реализуют в полной мере возможности наноиндустрии с возможностью одновременного обучения и взаимодействия с пользователем системы на естественном языке. Данные аспекты рассматривали такие ученые, как И.П. Павлов в концепции обучения и самоорганизации живых организмов; А.А. Ухтомский в работах о доминантах модели поведения; В.М. Бехтерев, на исследованиях которого основываются современные проекты по созданию киборгов, созданию систем искусственного интеллекта, понимающих человеческую речь. В связи с этим остается нераскрытым вопрос о духовной экзистенции, являющейся «самым высоким измерением онтологической структуры человека» [3. С. 20].

Сегодня также актуален вопрос о создании базы смысловой обработки визуально получаемой информации, которая позволит искусственному интеллекту воспринимать, понимать и расшифровывать графические объекты.

В современном социуме объективно появляется потребность в актуализации концептуальных построений, расширяющих возможности познания киберпространства, так как «с помощью информационно-коммуникационных технологий (через телевидение, Интернет) можно воздействовать на сознание человека и даже программировать его. Вообще, сегодня многие науки о человеке становятся во все большей степени поставщиками средств управления человеческим существом, проектирования его телесности и психики» [1. С. 4].

Алгоритм социального развития, как сегодня отмечается многими отечественными и зарубежными учеными, свидетельствует о том, что государство может и должно обеспечить стабильность, устойчивый рост и особенно безопасность современного общества только посредством высокого уровня развития науки, информационной культуры, промышленности, т.е. развитой высокоинтеллектуальной индустрии [4. С. 4]. Действительно, общая цель, форма и содержание информационной образовательной стратегии, формирующей личность человека, претерпевают изрядные изменения и оптимизацию относительно современных условий. В сложившейся ситуации мы мо- 
жем наблюдать стагнацию власти, некомпетентность в некоторых вопросах воздействия на сферу безопасности, общественные отношения, касающиеся нового явления - неотерроризма, представляющего собой комплексно реализованную агрессию с применением интеллектуальных ресурсов. К неотерроризму можно отнести и широкомасштабные изменения национального самосознания граждан, нарушающие единство, общность народа, проживающего многие века на одной территории, создавая условия для жесткого идеологического противостояния и военного конфликта. Большое влияние на создание сложившейся ситуации оказывают разрушающие действия финансовых корпораций, провоцирующих кризис внутри страны. Ярким примером неотерроризма служит контекст военно-политического модерна целого ряда стран мира в виде специализированной агрессии, реализующейся с помощью комплекса внешних и внутренних мероприятий военно-политического, финансово-экономического, а также духовно-информационного характера и содержания, основывающейся на применении политических технологий, с функцией контроля, используемых не всегда явно, воздействие которых на ход конфликта осуществляется систематически и опосредованно с широкой финансовой и медийной поддержкой.

Пролематика эволюции интернет-технологий зиждется на вопросах компьютеризации и развития технической и технологической составляющей процессов информатизации, глобальных процессов модернизации автоматизированных систем организации государственного управления, создания единого киберпространства, изменяя, в некоторой степени, природу человека. В связи с этим в будущем у человека «будут отсутствовать некоторые качества, которые до сих пор осложняли человеческую жизнь: он будет рационален, а не эмоционален, ряд традиционных ценностных установок у него просто исчезнут. В перспективе он может быть бессмертным, а его сознание перенесено с биологического носителя (каким является человеческое тело) на цифровой» [1. С. 5]. Конечно же, современные информационные технологии способствуют изменению ценностей, стереотипов, форм поведения, модели взаимоотношений индивидов, групп индивидов, политических институтов и органов государственной власти. Поэтому очевидна взаимосвязь сферы обеспечения защиты общества от воздействия систем искусственного интеллекта, их потенциала, применяющихся в области разработки, обеспечения и использования в различных сферах жизнедеятельности человека, в том числе и киберпространстве, оказывающем «огромное влияние на развитие экономики, политической жизни, культуры, техносферы, военного дела. Киберпространство - исключительно быстро развивающаяся область, причем все ещё плохо познанная (в значительной мере в силу того, что его познание требует как естественнонаучных и технических знаний, так и гуманитарных и общественнонаучных)» [6. С. 19]. Следовательно, в процессе эволюции киберпространства можно выделить некие черты действительности, трансформирующие реальность, тем самым изменяя потенциал, способности личности и общественные отношения в целом. Поэтому процесс обеспечения безопасности достаточно специфичен, в особенности с неповторимой многочисленной палитрой религиозно-культурных особенностей, ценностей, ментальности, провоцирующих новые потребности в формировании интересов и мировоз- 
зрения личности в рамках сложившихся условий современного информационного общества.

Процесс формирования и развития сферы безопасности современного информационного общества можно охарактеризовать историей его развития, коммуникационной архитектурой, изменениями геополитики, что приводит к возникновению опасностей, угроз, связанных с киберпространством и неотерорризмом. Нарастающие темпы развития информационного общества заключаются в интенсивном преобразовании, системности кризисов практически во всех сферах жизнедеятельности человека, а глобализация информационных потоков в киберпространстве - специфическая составляющая не только человека (рефлексия), но и общества в целом. Поэтому можно сделать следующий вывод: знания современного человека, его интеллект должны обеспечивать положительную динамику эволюции цивилизации, а не уничтожать экосистему, в том числе и человечество. Известен тот факт, что человек отличается от всех живых существ, поскольку способен познать социальное пространство, обладает речью, сознанием, интеллектом, способен накапливать знания, воздействовать на окружающий мир и созидать. Но необходимо помнить о постоянном непрерывном изменении сущности человека, а его объективная реальность «скрепляется в подобие целостности религиозными учениями, переселением народов, образованием единого информационного пространства, свободным обращением финансов, капиталов и мозгов. Человечество стремится согласовать деятельность в глобальных размерах, привлекая науку» [7. С. 105].

В заключение отметим, что системы искусственного интеллекта относятся к плавной, широкомасштабной, глобальной информационной макроэволюции, которые в полной мере трансформируют современного человека в человека техногенного, что влечет за собой применение методов кибернетического моделирования, нейропрограммирования, компьютерного моделирования наносистем. В связи с этим применение компьютерных технологий, использование нанобиотехнологий, глобальная актуализация киберпространства влияет не только на ценности, но и на поведение, форму общения, мировоззрение личности, что видоизменяет сущность бытия человека и оказывает воздействие на сферу безопасности общества, посредством взаимодействия пользователя и искусственного интеллекта на естественном языке в киберпространстве, обусловленном высокими достижениями человечества в сферах наноиндустрии, биоинженерии, биоинформатики и робототехники.

\section{Лuтература}

1. Лекторский В.А. Возможны ли науки о человеке? // Вопросы философии. 2015. № 5. C. $3-16$.

2. Бачинин В.А. Политология. Энциклопедический словарь. СПб.: Изд-во Михайлова В.А., 2005. $288 \mathrm{c}$.

3. Лебедев С.А., Лазарев Ф.В. Многомерный человек: онтология и методология исследования. М.: Изд-во МГУ, 2010. 96 с.

4. Филин С.A. Механизм реализации инновационной политики. М.: ИНИЦ Роспатента, 2005. $286 \mathrm{c}$. 
5. Абдрахманов Д.В. Информационное общество как объект конституционно-правового регулирования: к постановке проблемы // Проблемы права. 2015. № 5. С. 41-47.

6. Кокошин A.A. Национальные интересы, реальный суверенитет и национальная безопасность // Вопросы философии. 2015. № 10. С. 5-21.

7. Букреев В.И. Человек агрессивный (Истоки международного терроризма). М.: Флинта: МПСИ, 2007. $336 \mathrm{c}$.

Kvashnina Darya A. State Professional Educational Institution «The Yurga Technical School of Machine-Building and Information Technology» (Yurga, Russian Federation).

E-mail: kvashninada@gmail.com

DOI: 10.17223/1998863X/37/6

PHILOSOPHICAL ASPECTS OF THE ARTIFICIAL INTELLIGENCE IMPACT ON SOCIETY

Key words: artificial intelligence, security, robotics, nanotechnology, cyberspace.

The artificial intelligence interferes the world. In the 90th and the beginning of the 21 st century the artificial intelligence achieved the greatest success. Quantity of jobs where people, at a research of other planets, neutralization of a bomb replaces robots, studying of a volcano or just execution of boring housework as the cleaning increases. Computers can execute a number of functions: they can conduct cars and planes, to provide us news, chess of a game and soccer or to compose music. Now many production tasks are executed by industrial robots. It led to reduction of cost of production of various goods, including cars and electronics. The artificial intelligence is successfully applied in the majority of various areas, including medical diagnostics, exchange trade, control of the robot, the legislation, opening and toys. Industrial robots are also used for packing of industrial goods, transportation of goods in warehouses, in hospitals or removal of tiny electronic components with a big accuracy, speed and reliability. Scientists are interested in development of robots, similar to the person. But, whether robots are our best friends, or they are dangerous? It is still difficult to answer this question.

In the represented article highlights the issue related to artificial intelligence, biosafety nanoindustry and security spheres of modern society. Empirical evidence suggests that scientists need to pay particular attention to the objective difficulties arising in the creation of innovative projects and the use of updated technologies, promoting the development of artificial intelligence systems, design of computer systems capable of solving intellectual challenges, for example in the field of robotics and nanobiotechnology directly related to security sector of society. Artificial intelligence is the result of human activity, ability to think logically, to control their actions, to justify their decisions, he can adjust to changes in conditions. Active use of computer technology, nanobiotechnology, may enable radically change human reflection, change the cultural programs and communication technologies are affecting the characteristics of the individual and existential ambiguity of the existing social relations.

\section{References}

1. Lektorskiy, V.A. (2015) Vozmozhny li nauki o cheloveke? [Are the sciences about man possible?]. Voprosy filosofii. 5. pp. 3-16.

2. Bachinin, V.A. (2005) Politologiya. Entsiklopedicheskiy slovar' [Political science. The Encyclopedic Dictionary]. St. Petersburg: V.A. Mikhaylov.

3. Lebedev, S.A. \& Lazarev, F.V. (2010) Mnogomernyy chelovek: ontologiya i metodologiya issledovaniya [A multidimensional person: Ontology and methodology of research]. Moscow: Moscow State University.

4. Filin, S.A. (2005) Mekhanizm realizatsii innovatsionnoy politiki [The mechanism of implementation of innovation policy]. Moscow: INITs Rospatenta.

5. Abdrakhmanov, D.V. (2015) Information society as an object of constitutional and legal regulation: The problem. Problemy prava - The Issues of Law. 5. pp. 41-47. (In Russian).

6. Kokoshin, A.A. (2015) Natsional'nye interesy, real'nyy suverenitet i natsional'naya bezopasnost' [National interests, real sovereignty and national security]. Voprosy filosofii. 10. pp. 5-21.

7. Bukreev, V.I. (2007) Chelovek agressivnyy (Istoki mezhdunarodnogo terrorizma) [An aggressive man (Origins of international terrorism)]. Moscow: Flinta. 